\title{
Molecular and cellular mechanisms underlying the antidepressant effects of ketamine enantiomers and its metabolites
}

\author{
Chun Yang ${ }^{1,4}$, Jianjun Yang $\mathbb{1}^{2}$, Ailin Luo ${ }^{1}$ and Kenji Hashimoto $\mathbb{B}^{3}$
}

\begin{abstract}
Although the robust antidepressant effects of the N-methyl-D-aspartate receptor (NMDAR) antagonist ketamine in patients with treatment-resistant depression are beyond doubt, the precise molecular and cellular mechanisms underlying its antidepressant effects remain unknown. NMDAR inhibition and the subsequent a-amino-3-hydroxy-5methyl-4-isoxazolepropionic acid receptor (AMPAR) activation are suggested to play a role in the antidepressant effects of ketamine. Although (R)-ketamine is a less potent NMDAR antagonist than (S)-ketamine, $(R)$-ketamine has shown more marked and longer-lasting antidepressant-like effects than (S)-ketamine in several animal models of depression. Furthermore, non-ketamine NMDAR antagonists do not exhibit robust ketamine-like antidepressant effects in patients with depression. These findings suggest that mechanisms other than NMDAR inhibition play a key role in the antidepressant effects of ketamine. Duman's group demonstrated that the activation of mammalian target of rapamycin complex 1 (mTORC1) in the medial prefrontal cortex is reportedly involved in the antidepressant effects of ketamine. However, we reported that MTORC1 serves a role in the antidepressant effects of (S)-ketamine, but not of $(R)$-ketamine, and that extracellular signal-regulated kinase possibly underlie the antidepressant effects of (R)-ketamine. Several lines of evidence have demonstrated that brain-derived neurotrophic factor (BDNF) and its receptor, tyrosine kinase receptor $B(T r k B)$, are crucial in the antidepressant effects of ketamine and its two enantiomers, $(R)$-ketamine and (S)-ketamine, in rodents. In addition, (2R,6R)-hydroxynormetamine [a metabolite of (R)-ketamine] and (S)-norketamine [a metabolite of (S)-ketamine] have been shown to exhibit antidepressant-like effects on rodents through the BDNF-TrkB cascade. In this review, we discuss recent findings on the molecular and cellular mechanisms underlying the antidepressant effects of enantiomers of ketamine and its metabolites. It may be time to reconsider the hypothesis of NMDAR inhibition and the subsequent AMPAR activation in the antidepressant effects of ketamine.
\end{abstract}

\section{Introduction}

Antidepressants, including selective serotonin reuptake inhibitors (SSRIs) and selective noradrenaline reuptake inhibitors (SNRIs), are widely prescribed for the treatment of depression in patients with major depressive disorder (MDD). However, there is a significant time lag of weeks

Correspondence: Kenji Hashimoto (hashimoto@faculty.chiba-u.jp) 'Department of Anesthesiology, Tongji Hospital, Tongji Medical College, Huazhong University of Science and Technology, Wuhan, China

2Department of Anesthesiology, The First Affiliated Hospital of Zhengzhou University, Zhengzhou, China

Full list of author information is available at the end of the article. to months for the antidepressant effects of these drugs to be achieved in patients with $\mathrm{MDD}^{1}$. In addition, approximately one-third of patients with MDD do not experience satisfactory therapeutic benefits following treatment with SSRIs or SNRIs ${ }^{1}$. Importantly, the delayed onset of these antidepressants is extremely harmful to patients with depression who experience suicidal ideation $^{2,3}$. Therefore, the development of rapid-acting and robust antidepressants is imperative to relieve the symptoms of severe depression and suicidal ideation in patients with MDD or bipolar disorder (BD) ${ }^{4-12}$.

\section{(c) The Author(s) 2019}

(c) (i) Open Access This article is licensed under a Creative Commons Attribution 4.0 International License, which permits use, sharing, adaptation, distribution and reproduction cc) in any medium or format, as long as you give appropriate credit to the original author(s) and the source, provide a link to the Creative Commons license, and indicate if changes were made. The images or other third party material in this article are included in the article's Creative Commons license, unless indicated otherwise in a credit line to the material. If material is not included in the article's Creative Commons license and your intended use is not permitted by statutory regulation or exceeds the permitted use, you will need to obtain permission directly from the copyright holder. To view a copy of this license, visit http://creativecommons.org/licenses/by/4.0/. 
In 2000, Berman et al. ${ }^{13}$ demonstrated that a subanesthetic dose $(0.5 \mathrm{mg} / \mathrm{kg})$ of ketamine, an $N$-methyl-Daspartate receptor (NMDAR) antagonist, produced rapidacting and sustained antidepressant effects in patients with MDD. This is a first double-blind, placebo-controlled study of ketamine in depressed patients ${ }^{13}$. Subsequently, Zarate et al. ${ }^{14}$ replicated the rapid-acting and sustained antidepressant effects of ketamine for patients with treatment-resistant MDD. In addition, ketamine possesses robust antidepressant effects in patients with bipolar depression $^{15-18}$. Ketamine has been shown to alleviate suicidal ideation in patients with treatment-resistant $\mathrm{MDD}^{19-21}$. Several meta-analyses revealed that ketamine has robust antidepressant and anti-suicidal ideation effects in depressed patients with treatment-resistant MDD or $\mathrm{BD}^{2,3,22,23}$.

The antidepressant effects of ketamine have attracted increasing academic attention due to its effects being rapid-acting and long-lasting effects in treatment-resistant depression $^{8,12,24}$. Although ketamine has a robust antidepressant effect, its side effects may limit its widespread use for the treatment of depression ${ }^{12,25-31}$. Ketamine has detrimental side effects, which include psychotomimetic effects, dissociative effects, and abuse liability; which may be associated with the blockade of $\mathrm{NMDAR}^{25,26,32}$. It is known that dissociative symptoms following ketamine infusion are not associated with its clinical benefits ${ }^{24}$, suggesting that NMDAR inhibition may not serve a key role in the antidepressant effects of ketamine. Fava et al. ${ }^{33}$ also reported that there were no statistically significant correlations between Clinician Administered Dissociative States Scale (CADSS) scores $40 \mathrm{~min}$ after the ketamine infusion and Hamilton Depression Rating Scale-6 (HAMD-6) scores at day 1 and day 3 in treatmentresistant patients with depression, in contrast to the hypothesis by Luckenbaugh et al. $^{34}$. In addition, brainimaging findings suggest that reduced subgenual anterior cingulate cortex is implicated in the antidepressant effects of ketamine in humans ${ }^{35,36}$. However, the precise molecular and cellular mechanisms underlying its antidepressant effects remain unclear. In this review article, recent findings on the molecular and cellular mechanisms underlying the antidepressant effects of enantiomers of ketamine and its metabolites are summarized.

\section{Enantiomers of ketamine}

Ketamine ( $\mathrm{Ki}=0.53 \mu \mathrm{M}$ for NMDAR) (Fig. 1) is a racemic mixture consisting of equal parts of $(R)$-ketamine (or arketamine) and (S)-ketamine (or esketamine). The binding affinity of $(S)$-ketamine $(\mathrm{Ki}=0.30 \mu \mathrm{M})$ for NMDAR is $\sim 4$ fold greater than that of $(R)$-ketamine $(\mathrm{Ki}=1.4 \mu \mathrm{M})$ (Fig. 1) ${ }^{37}$. Furthermore, the anesthetic potency of $(S)$-ketamine is $\sim 3-4$-fold greater and the undesirable psychotomimetic side effects are greater than those of
$(R)$-ketamine ${ }^{38}$. We reported that $(R)$-ketamine has more potent and longer-lasting antidepressant-like effects than $(S)$-ketamine in neonatal dexamethasone-treated, chronic social defeat stress (CSDS), and learned helplessness (LH) models of depression ${ }^{39,40}$. Subsequent studies have also shown that $(R)$-ketamine has more potent antidepressantlike effects than $(S)$-ketamine in rodents ${ }^{41,42}$. A recent study showed that the order of antidepressant-like effects in a CSDS model following the intranasal administration is $(R)$ ketamine $>(R, S)$-ketamine $>(S)$-ketamine ${ }^{43}$, and that the order of side effects in rodents is $(S)$-ketamine $>(R, S)$ ketamine $>(R)$-ketamine ${ }^{43}$. The side effects of $(R)$-ketamine in rodents were lower than those of $(S)$-ketamine ${ }^{40,43-45}$. A positron emission tomography study showed a marked reduction in dopamine $D_{2 / 3}$ receptor binding in the conscious monkey striatum following a single intravenous infusion of $(S)$-ketamine but not that of $(R)$-ketamine, suggesting that the $(S)$-ketamine-induced dopamine release may be associated with acute psychotomimetic and dissociative side effects in humans ${ }^{46}$.

In 1995, Mathisen et al. ${ }^{47}$ reported that the incidence of psychotomimetic side effects of $(S)$-ketamine in patients with orofacial pain was higher than that of $(R)$-ketamine, despite the dose of $(S)$-ketamine $(0.45 \mathrm{mg} / \mathrm{kg})$ being lower than that of $(R)$-ketamine $(1.8 \mathrm{mg} / \mathrm{kg})$. In addition, Vollenweider et al. ${ }^{48}$ reported that $(R)$-ketamine did not produce psychotic symptoms in healthy subjects and that the majority experienced a state of relaxation, whereas the same dose of $(S)$-ketamine caused psychotic reactions including depersonalization and hallucinations. These findings suggest that $(S)$-ketamine contributes to the acute side effects of ketamine, whereas $(R)$-ketamine may not be associated with these side effects ${ }^{49}$. Importantly, non-ketamine NMDAR antagonists (i.e., memantine, traxoprodil, lanicemine, rapastinel, and AV-101) did not exhibit robust ketamine-like antidepressant effects in patients with $\mathrm{MDD}^{12,22,23}$. These clinical findings suggest that NMDAR may not be the primary target for the antidepressant effects of ketamine.

Taken together, $(R)$-ketamine is considered to be a safer antidepressant than $(R, S)$-ketamine and $(S)$-ketamine in humans ${ }^{12,50-52}$. On March 5, 2019, the US Food Drug Administration (FDA) approved $(S)$-ketamine nasal spray for treatment-resistant depression. However, it is only available through a restricted distribution system, under a Risk Evaluation and Mitigation Strategy due to the risk of serious side adverse outcomes. A clinical trial of $(R)$ ketamine in humans is currently underway by Perception Neuroscience, Inc. ${ }^{12}$.

\section{Mechanisms of action of ketamine's antidepressant action NMDAR inhibition and subsequent AMPAR activation}

In 1990, Skolnick' group reported antidepressant-like effects of NMDAR antagonists in rodents ${ }^{53,54}$. Although 

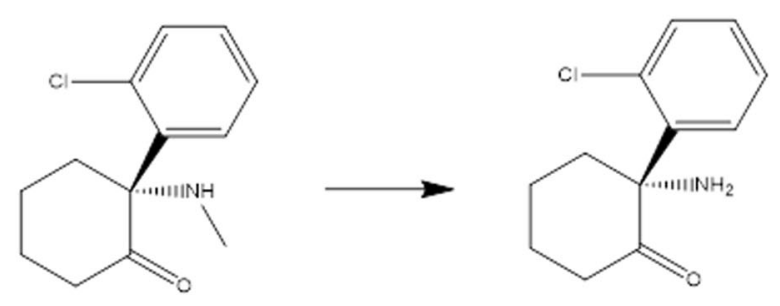

(R)-Norketamine $(\mathrm{Ki}=13 \mu \mathrm{M})$ $(\mathrm{Ki}=1.40 \mu \mathrm{M})$<smiles>[3H][V]</smiles><smiles>CN[C@@]1(c2ccccc2Cl)CCC[C@@H](O)C1=O</smiles>

$(2 R, 6 R)-H K$ $(\mathrm{Ki}>10 \mu \mathrm{M})$<smiles>CN[C@@]1(c2ccccc2Cl)CCCCC1=O</smiles>

(S)-Ketamine $(\mathrm{Ki}=0.30 \mu \mathrm{M})$<smiles>[3H]</smiles><smiles>CN[C@@]1(c2ccccc2Cl)CCC[C@@H](O)C1=O</smiles>

$(2 S, 6 S)-H K$ $(\mathrm{Ki}=10 \mu \mathrm{M})$

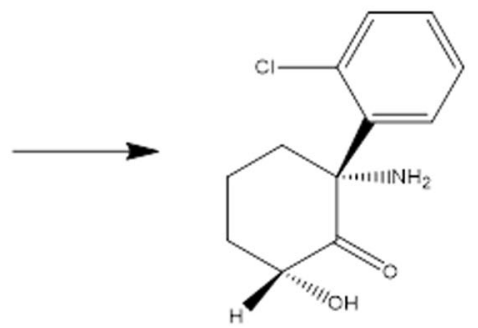

\section{(2R,6R)-HNK}

(Ki > $10 \mu \mathrm{M}$ )<smiles></smiles>

(S)-Norketamine $(\mathrm{Ki}=1.7 \mu \mathrm{M})$ $\gamma$

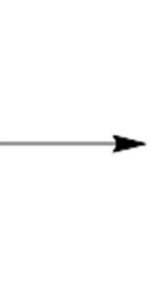

\section{(2S,6S)-HNK}

$(\mathrm{Ki}>10 \mu \mathrm{M})$<smiles>CC1C=CC(=O)[C@@](N)(c2ccccc2Cl)CC1</smiles>

(R)-DHNK ( $\mathrm{Ki}=10 \mu \mathrm{M})$<smiles>CCCCC[C@]1(N)CCC=CC1=O</smiles>

(S)-DHNK

$(\mathrm{Ki}>10 \mu \mathrm{M})$

Fig. 1 Chemical structure of enantiomers of ketamine and its metabolites. (R)-ketamine [or (S)-ketamine] is initially metabolized to (R)norketamine [or (S)-norketamine] by either CYP2B6 or CYP3A4, and then metabolized to (R)-dehydronorketamine (DHNK) [or (S)-DHNK]. Hydroxylation of (R)-norketamine [or (S)-norketamine] at the sixth position by CYP2A6 results in (2R,6R)-hydroxynorketamine (HNK) [or (2S,6S)-HNK]. $(R)$-ketamine [or (S)-ketamine] is also metabolized to $(2 R, 6 R)$-hydroxyketamine $(H K)$ [or $(2 S, 6 S)$-HK], then to $(2 R, 6 R)$-HNK $[\text { or }(2 S, 6 S) \text {-HNK }]^{49}$. The values in the parenthesis are the Ki value for the NMDAR 37,41 


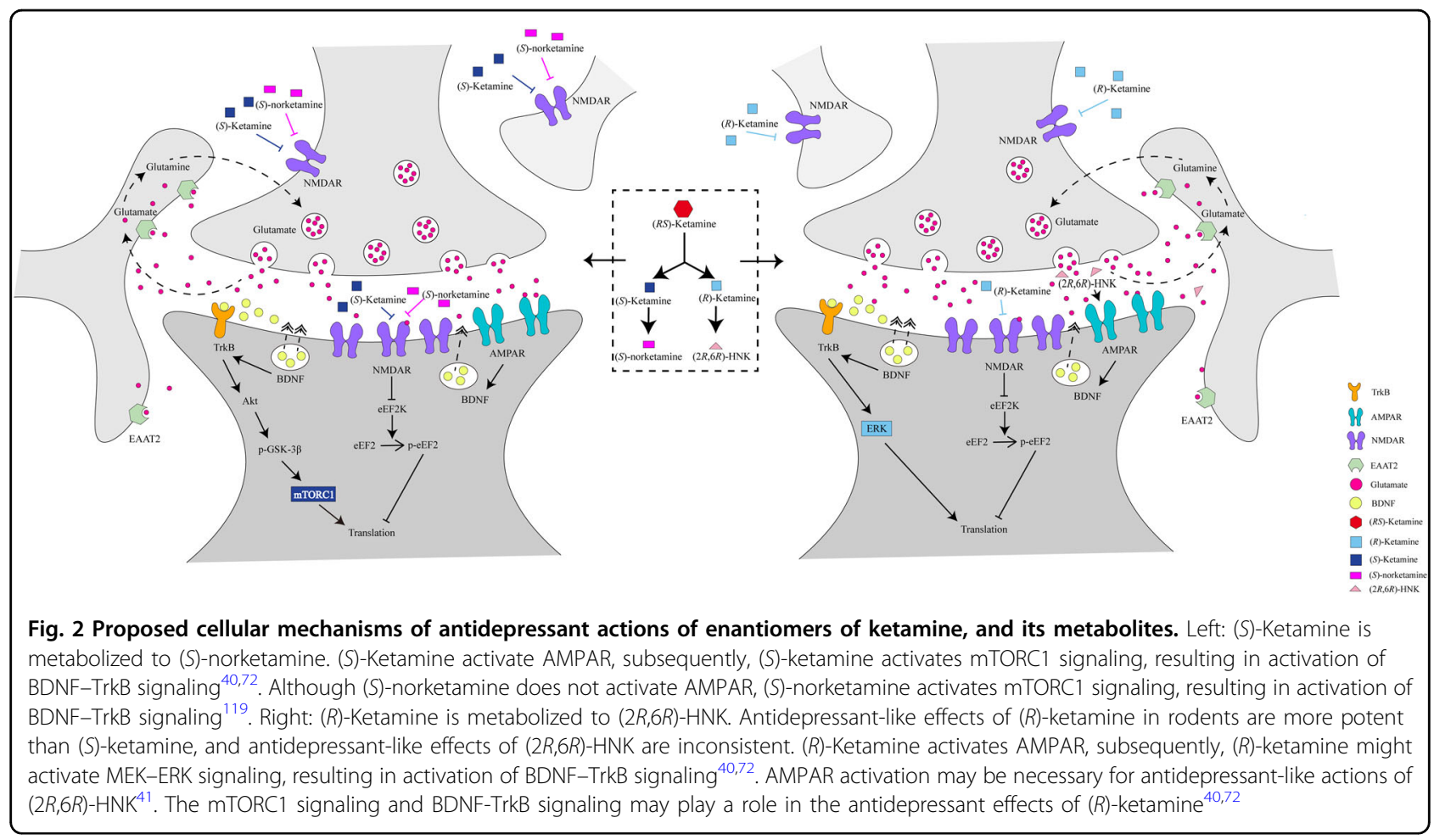

the precise mechanisms underlying the antidepressant effects of ketamine and its metabolites remain unclear, their rapid antidepressant effects are considered to occur via the blockade of NMDARs located on inhibitory interneurons (Fig. 2). This blockage leads to the disinhibition of pyramidal cells, resulting in a burst of glutamatergic transmission. In 2008, Maeng et al. ${ }^{55}$ reported that $\alpha$-amino-3-hydroxy-5-methyl-4-isoxazolepropionic acid receptor (AMPAR) antagonists blocked the antidepressant-like effects of ketamine in rodents, suggesting a role of AMPAR activation in the antidepressantlike effects of ketamine. It has been suggested that increased glutamate release activates AMPARs, as AMPAR antagonists inhibit the antidepressant-like effects of ketamine and its two enantiomers ${ }^{40-42,56-58}$. Collectively, it appears that AMPAR activation serves an important role in the antidepressant-like effects of ketamine and its enantiomers ${ }^{5-10,40,58}$.

In contrast, non-ketamine NMDAR antagonists did not produce robust ketamine-like antidepressant effects in depressed patients ${ }^{12,22,23}$. In addition, $(R)$-ketamine has more potent antidepressant-like effects in rodents than $(S)$-ketamine, despite $(R)$-ketamine being less potent at NMDAR inhibition than (S)-ketamine. A recent functional MRI (fMRI) study in conscious rats demonstrated that, similar to the potent and selective NMDAR antagonist $\quad(+)-\mathrm{MK}-801 \quad(0.1 \mathrm{mg} / \mathrm{kg}), \quad(R, S)$-ketamine $(10 \mathrm{mg} / \mathrm{kg})$, and $(S)$-ketamine $(10 \mathrm{mg} / \mathrm{kg})$ produced a significant positive response in the cortex, nucleus accumbens, and striatum. In contrast, (R)-ketamine $(10 \mathrm{mg} / \mathrm{kg})$ produced negative response in the several regions $^{59}$. This study suggests that $(R)$-ketamine and $(S)$ ketamine induce completely different fMRI response patterns in rat brain, and that $(S)$-ketamine-induced pattern is similar to $(+)$-MK-801. Collectively, it is likely that at the antidepressant-like dose $(10 \mathrm{mg} / \mathrm{kg}),(R)$-ketamine does not produce NMDAR antagonist-like brain activation in the brain.

Therefore, it may be time to reconsider the hypothesis of NMDAR inhibition and the subsequent AMPAR activation in the antidepressant effects of ketamine and its two enantiomers. In addition to NMDA inhibition and AMPAR activation, other important pathways, including mechanistic target of rapamycin (mTOR), the brainderived neurotrophic factor (BDNF)-tyrosine kinase receptor $B$ (TrkB) pathway, may be involved in the antidepressant-like effects of ketamine, as discussed below.

\section{Monoaminergic systems}

A recent study using in vivo microdialysis showed that $(R)$-ketamine and (S)-ketamine acutely increased serotonin (5-HT: 5-hydroxytryptamine) release in the PFC in a dose-dependent manner, and the effect of $(R)$-ketamine was greater than that of $(S)$-ketamine ${ }^{60}$. In contrast, $(S)$ ketamine caused a robust increase in dopamine release compared with $(R)$-ketamine. Differential effects between $(R)$-ketamine and $(S)$-ketamine were also observed in a LPS-induced model of depression. An AMPAR antagonist 
NBQX attenuated (S)-ketamine-induced, but not $(R)$ ketamine-induced 5-HT release, whereas NBQX blocked DA release induced by both enantiomers. This paper suggests differences between $(R)$-ketamine and $(S)$-ketamine in their abilities to induce prefrontal 5-HT and dopamine ${ }^{60}$. Furthermore, Zhang et al. ${ }^{61}$ reported that 5 HT depletion did not affect the antidepressant-like effects of $(R)$-ketamine in a CSDS model, suggesting that 5-HT does not play a major role in the antidepressant-like effects of $(R)$-ketamine.

A recent study showed that dopamine $D_{1}$ receptor activation in the medial PFC may play a role in the antidepressant-like effects of ketamine ${ }^{62}$. However, Chang et al. ${ }^{63}$ reported that the pretreatment with dopamine $D_{1}$ receptor antagonist did not block the antidepressant-like effects of $(R)$-ketamine in a CSDS model, suggesting that dopamine $D_{1}$ receptors may not play a major role in the antidepressant-like actions of $(R)$-ketamine, consistent with the previous report ${ }^{64}$.

Collectively, it is unlikely that monoamines such as 5HT and dopamine do not play a key role in the antidepressant-like effects of ketamine and its enantiomers although the monoaminergic system may play a role in their other pharmacological effects. A further detailed study is needed.

\section{Mechanistic target of rapamycin complex 1 (mTORC1)}

mTOR is an atypical serine/threonine protein kinase consisting of 2549 amino acids belonging to the phosphatidylinositol 3-kinase-related kinase family, which combines with several proteins to form two different complexes, mTORC1 and mTORC2 ${ }^{65}$. In addition, the signaling pathway controlled by mTOR can regulate physiological function in the central nervous system, such as neuronal development, synaptic plasticity, memory storage, and cognitive function ${ }^{66}$.

In 2010, Li et al. demonstrated that rapamycin, an mTOR inhibitor, inhibited the antidepressant-like effects of ketamine in rodents, which acted by increasing the number of synaptic proteins and synaptic spine density by rapidly activating the $\mathrm{mTORC1}$-signaling pathway in the medial prefrontal cortex $(\mathrm{PFC})^{56}$. In a forced swimming test, ketamine decreased the immobility time and increased the levels of hippocampal mTOR and BDNF, suggesting that the antidepressant-like effects of ketamine may be associated with increased hippocampal levels of mTOR and $\mathrm{BDNF}^{67}$. Furthermore, tramadol, an analgesic agent, enhanced the antidepressant-like effects of ketamine by increasing mTOR levels in the rat hippocampus and $\mathrm{mPFC}^{68}$. In addition, ketamine and its metabolites [i.e., norketamine and (2S,6S)-hydroxynorketamine $(\mathrm{HNK})]$ may produce an antidepressant-like effect by increasing the phosphorylation level of mTOR and its downstream targets ${ }^{69}$. By contrast, rapamycin can cause neurobehavioral changes, including anxiety-like behavior, in rats and can impede the antidepressant-like effects of ketamine $^{70}$. In addition, neuropeptide VGF (non-acronymic) knockdown attenuated the rapid antidepressantlike effects of ketamine by reducing mTOR phosphorylation $^{71}$. In dorsal raphe neurons, ketamine transiently increased the neurotransmission mediated by spontaneous AMPAR via mTOR signaling ${ }^{72}$. Furthermore, activation of mTOR in the PFC was involved in the antidepressant-like effects of ketamine, whereas inhibition of this pathway may protect the brain from oxidative stress or endoplasmic reticulum stress ${ }^{73,74}$. The mood stabilizer lithium, a GSK-3 inhibitor, can indirectly activate mTORC1 signaling, thereby enhancing the antidepressant-like effects of ketamine ${ }^{75}$. In addition, we previously reported that ketamine-induced antidepressant-like effects are associated with the AMPARmediated upregulation of mTOR and BDNF in the hippocampus and $\mathrm{PFC}^{76}$. Collectively, it is likely that mTORC1 signaling serves an important role in the mechanism underlying the antidepressant-like effects of ketamine.

Although these aforementioned studies support the role of mTORC1 in the antidepressant-like effect of ketamine, inconsistent results have emerged in subsequent studies. Autry et al. ${ }^{57}$ showed that the level of phosphorylated mTOR was not altered in the hippocampus of control and $B d n f$-knockout mice following acute administration of ketamine, and that the antidepressant-like effects of ketamine in wild-type mice were not affected by rapamycin. In addition, another study showed no significant changes in the levels of phosphorylated mTOR in the hippocampus and prefrontal cortex of mice following administration of ketamine or $(2 R, 6 R)$-HNK, whereas the levels of phosphorylated eEF2 and BDNF were significantly increased in the hippocampus following administration of ketamine or $(2 R, 6 R)-\mathrm{HNK}^{41}$. This increase may partially explain the mechanisms underlying the sustainable antidepressant-like effects of ketamine ${ }^{41}$. Of note, we reported that mTORC1 serves a major role in the antidepressant effect of $(S)$-ketamine, but not $(R)$ ketamine, in a CSDS model ${ }^{77}$. The antidepressant effects of $(R)$-ketamine may be mediated by the activation of ERK as pretreatment with SL327 (an ERK inhibitor) inhibited the antidepressant effects of $(R)$-ketamine ${ }^{77}$.

There are few clinical studies reporting the role of mTORC1 in the antidepressant effects of ketamine in depressed patients. Denk et $\mathrm{al}^{78}$ reported the first evidence of increased phosphorylated mTOR protein in the blood from a patient with MDD following a single injection of $(S)$-ketamine. Furthermore, we reported that the plasma levels of phosphorylated mTOR, GSK-3 $\beta$, and eEF2 were significantly increased following a single injection of ketamine ${ }^{79}$. It is, therefore, of interest to 
investigate whether $(R)$-ketamine can influence ERK and its phosphorylation in the blood from patients with MDD or BD.

A recent randomized, placebo-controlled clinical study demonstrated that pretreatment with rapamycin did not alter the acute effects of ketamine in patients with treatment-resistant MDD, whereas its combination with ketamine prolonged the antidepressant effect of ketamine and the response rate 2 weeks following treatment ${ }^{80}$. At present, there is no evidence that a low dose of rapamycin can achieve sufficient brain levels to inhibit mTOR. It is also suggested that rapamycin may produce beneficial effects through the inflammatory system in the periphery, although further investigation is required. Taken together, the role of mTORC1 in the antidepressant effect of ketamine in patients with MDD remains contradictory. Further investigation using a larger sample size is required to determine the role of mTORC1 in the antidepressant effects of ketamine and its metabolites in patients with MDD.

\section{BDNF}

Multiple lines of evidence show that BDNF and its receptor TrkB serve a critical role in the pathogenesis of depression and therapeutic mechanisms of antidepressants ${ }^{81-87}$. In 2011, Autry et al. ${ }^{57}$ reported that the rapid-acting antidepressant effects of ketamine depend on the rapid synthesis of BDNF, as ketamine did not elicit antidepressant-like effects in inducible $B d n f$-knockout mice, indicating a key role of the BDNF-TrkB cascade in the antidepressant effects of ketamine. Subsequent studies have supported the role of the BDNF-TrkB cascade in the antidepressant effects of ketamine ${ }^{67,76}$. In addition, the TrkB inhibitor ANA-12 significantly inhibited the rapid and long-lasting antidepressant effects of $(R)$-ketamine, and $(S)$-ketamine in a CSDS model ${ }^{40}$. Furthermore, $(R)$ ketamine produced more marked beneficial effects on reduced synaptogenesis and the BDNF-TrkB cascade in the PFC and hippocampus (i.e., CA3 and DG) of CSDSsusceptible mice than $(S)$-ketamine ${ }^{40}$. It has also been reported that the regulation of glutamate transporter 1 on astrocytes through the activation of TrkB is involved in the beneficial effects of ketamine on behavioral abnormalities and morphological changes in the hippocampus of chronic unpredictable mild stress (CUMS)-exposed rats ${ }^{88}$. A recent study showed that ketamine restores depressionlike phenotypes in CUMS-exposed vulnerable rats by rescuing the dendritic trafficking of $B d n f$ mRNA $^{89}$. In addition, the ketamine-induced regulation of TrkB is independent of $\mathrm{HNK}^{90}$. Collectively, it is likely that longlasting activation of the BDNF-TrkB cascade in the PFC and hippocampus may be implicated in the long-lasting antidepressant effects of ketamine and its enantiomers.

\section{Synaptogenesis}

Preclinical studies have shown that ketamine rapidly induces synaptogenesis and reverses the synaptic deficits caused by chronic stress, resulting in its antidepressantlike effects ${ }^{56,80-94}$. We reported that ketamine and its two enantiomers, improved decreased spine density in the mPFC of CSDS-susceptible mice 7 or 8 days following a single dose ${ }^{40,95}$, suggesting long-lasting effects on synaptogenesis. A recent study using single-cell two-photon calcium imaging in awake mice showed that the effects of ketamine on spine formation in the PFC were slower: spine formation rates were not significantly altered at 3-6 h following a single injection of ketamine, but were markedly altered at $12-24 \mathrm{~h}^{96}$. This suggests that dendritic spine formation in the PFC was required for the sustained antidepressant effects of ketamine but not for its acute antidepressant effects. By contrast, Zhang et al. ${ }^{97}$ reported that $(R)$-ketamine rapidly $(<3 \mathrm{~h})$ ameliorated the decreased spine density in the medial PFC and hippocampus of CSDS susceptible mice, resulting in its rapid acting antidepressant-like effects in rodents. In addition, a recent study showed that $(S)$-ketamine rapidly $(<1 \mathrm{~h})$ reversed dendritic spine deficits in CA1 pyramidal neurons of Flinders Sensitive rats with a depression-like phenotype $^{98}$. Therefore, further investigation of the acute effects of ketamine and its enantiomers in the dendritic spine deficits of rodents with depression-like phenotype is required.

\section{Opioid system}

It is well known that ketamine can interact with opioid receptors. The order of affinity for opioid receptor subtypes is mu > kappa > delta. The binding of $(S)$-ketamine is also known to be $\sim 2-4$-fold stronger to mu and kappa receptors than that of $(R)$-ketamine ${ }^{38,99}$. In addition, ketamine has been reported to exert antagonistic effects at both mu and kappa opioid receptors, suggesting that ketamine use does not lead to opioid addiction ${ }^{99}$. Recently, pretreatment with an opiate receptor antagonist naltrexone $(50 \mathrm{mg})$ significantly inhibited the antidepressant and anti-suicidal effects of ketamine, but not its dissociative effects, in patients with treatment-resistant MDD, suggesting that activation of the opioid system is necessary to produce the rapid-acting antidepressant effects of ketamine ${ }^{100,101}$. By contrast, Yoon et al. ${ }^{102}$ demonstrated that pretreatment with naltrexone did not affect the antidepressant effects of ketamine in depressed patients with alcohol use disorder. Furthermore, ketamine had antidepressant efficacy in patients concurrently on high-affinity mu opioid receptor agonists (i.e., buprenorphine, methadone, or naltrexone), suggesting that the chronic use of opioid receptor agonists is not a contraindication for ketamine treatment for depression ${ }^{103}$. 
Therefore, the role of the opioid system in the antidepressant effects of ketamine is controversial.

Recently, we reported that pretreatment with naltrexone did not inhibit the antidepressant-like effects of ketamine in a CSDS model and inflammation-induced model of depression, suggesting that the opioid system may not serve a role in the antidepressant-like effects of ketamine $e^{104}$. However, further clinical trials with a large sample size are required to better understand whether opioid receptor activation is necessary for the antidepressant and anti-suicidal effects of ketamine in patients with MDD and BD.

\section{(2R,6R)-hydroxynorketamine (HNK)}

Ketamine is metabolized to norketamine via $\mathrm{N}$-demethylation by cytochrome P450 (CYP) enzymes in the liver (Fig. 1). Following $\mathrm{N}$-demethylation, norketamine is further metabolized to HNKs and dehydronorketamine (DHNK) (Fig. 1) ${ }^{49}$. Several metabolites of HNKs, including $(2 R, 6 R ; 2 S, 6 S)$-HNK and $(2 S, 6 R ; 2 R, 6 S)$-HNK, were detected in human plasma following ketamine infusion ${ }^{105}$.

In 2016, Zanos et al. demonstrated that the generation of $(2 R, 6 R)$-HNK $(\mathrm{Ki}>10 \mu \mathrm{M}$ for NMDAR) (Fig. 1) in the body was essential for the antidepressant-like effects of $(R$, $S)$-ketamine in rodents, and that NMDAR may not be involved in the antidepressant-like effects of $(2 R, 6 R)$ $\mathrm{HNK}^{41}$. Of note, $(2 R, 6 R)$-HNK did not produce detrimental side effects (i.e., hyperlocomotion, pre-pulse inhibition deficits, motor incoordination, and abuse liability) of ketamine in rodents at a high dose ${ }^{37}$. Subsequently, several groups have replicated the antidepressant-like effects of $(2 R, 6 R)$-HNK in rodents ${ }^{106,107}$. Furthermore, Lumsden et al. ${ }^{108}$ demonstrated that antidepressant-relevant concentrations of $(2 R, 6 R)$-HNK did not inhibit NMDAR function, whereas a high concentration $(50 \mu \mathrm{M})$ of $(2 R, 6 R)$-HNK inhibited NMDAR synaptic function ${ }^{109}$. It is also suggested that the metabotropic glutamate $\mathrm{mGlu}_{2}$ receptors are involved in the antidepressant-like effects of $(2 R, 6 R)$-HNK as the antidepressant-like effects of $(2 R, 6 R)$ HNK were absent in mice lacking the Grm2 gene, but not the Grm3 gene ${ }^{110}$. It is currently unknown whether mGlu receptors play a role in the antidepressant-like effects of $(R)$-ketamine in rodents.

By contrast, our group found that $(2 R, 6 R)-\mathrm{HNK}$ did not exhibit antidepressant-like effects in rodent models of depression, however, its parent compound $(R)$-ketamine exhibited robust antidepressant-like effects in the same models ${ }^{111-116}$. Pretreatment with two CYP inhibitors (ticlopidine hydrochloride and 1-aminobenzotriazole) prior to $(R)$-ketamine $(3 \mathrm{mg} / \mathrm{kg})$ injection increased the levels of $(R)$-ketamine in the blood, whereas $(2 R, 6 R)$-HNK was not detected in the blood. In the presence of these CYP inhibitors, $(R)$-ketamine $(3 \mathrm{mg} / \mathrm{kg})$ exhibited antidepressant-like effects, although the same dose did not exhibit antidepressant-like effects in the absence of CYP inhibitors ${ }^{117}$. In addition, we reported that the direct infusion of $(R)$-ketamine in brain regions produced antidepressant-like effects in a rat LH model, suggesting that $(R)$-ketamine itself, but not its metabolite, produced antidepressant-like effects ${ }^{118}$. These data suggest that the metabolism of $(2 R, 6 R)$-HNK from $(R)$-ketamine is not essential for the antidepressant-like effects of $(R)$-ketamine ${ }^{119,120}$. The US FDA approved $(S)$-ketamine, however, $(2 R, 6 R)$-HNK is not prepared from $(S)$-ketamine, indicating that $(2 R, 6 R)-\mathrm{HNK}$ is not essential for the antidepressant effects of ketamine ${ }^{12}$. A recent study from Zanos et al. ${ }^{121}$ showed that $(R)$-ketamine may exert antidepressant-like effects partly via conversion to $(2 R, 6 R)$-HNK. The conclusion was toned down 3 years after the first publication of $(2 R, 6 R)-\mathrm{HNK}^{41}$.

It has also been demonstrated that $(2 R, 6 R)$-HNK exerts antidepressant effects through AMPAR activation as AMPAR antagonist inhibited the antidepressant effects of $(2 R, 6 R)-\mathrm{HNK}^{41}$. By contrast, at a clinically relevant unbound brain concentration $(0.01-10 \mu \mathrm{M}),(2 R, 6 R)$ HNK did not bind orthosterically or directly to functionally activated AMPARs ${ }^{122}$. Furthermore, $(2 R, 6 R)$ HNK failed to evoke AMPAR-centric changes in any electrophysiological endpoint from adult rodent hippocampal sections ${ }^{122}$. Unfortunately, the AMPAR potentiator Org 26576 did not have antidepressant effects in depressed patients ${ }^{123}$. At present, a clinical trial of TAK653, an AMPAR potentiator with minimal agonistic effects, is underway in patients with treatment-resistant depression (NCT03312894). Further investigation on the role of AMPAR in the action of enantiomers of ketamine and its metabolites (norketamine and HNK) is required.

A recent study demonstrated that a single injection of $(2 R, 6 R)-\mathrm{HNK} \quad(1-10 \mathrm{mg} / \mathrm{kg})$, but not $(2 S, 6 S)$-HNK, increased aggressive behaviors through AMPARdependent mechanisms in the ventrolateral periaqueductal gray matter ${ }^{124}$. A clinical trial of $(2 R, 6 R)$-HNK in humans is currently underway at the National Institute of Mental Health, USA ${ }^{12}$. The aggressive effects of $(2 R, 6 R)$ HNK in humans warrant investigation. In addition, it is of interest to compare the antidepressant effects of $(R)$ ketamine and its final metabolite $(2 R, 6 R)$-HNK in patients with MDD.

\section{(S)-Norketamine}

$(S)$-Ketamine is metabolized to $(S)$-norketamine $[\mathrm{Ki}=$ $1.70 \mu \mathrm{M}$ for NMDAR] by CYP enzymes (Fig. 1). We reported that $(S)$-norketamine, but not $(R)$-norketamine, exhibits rapid and sustained antidepressant-like effects in CSDS and inflammation models of depression. The potency of the antidepressant-like effects of $(S)$-norketamine is similar to that of its parent compound $(S)$-ketamine, although the antidepressant-like effects of 
$(S)$-norketamine are less potent than those of $(R)$-ketamine ${ }^{125}$. Unlike $(R, S)$-ketamine and its enantiomers, AMPAR antagonists do not inhibit the antidepressant effects of (S)-norketamine, suggesting that AMPAR activation appears to be unnecessary for the antidepressantlike effects of $(S)$-norketamine ${ }^{125}$. Therefore, it is unlikely that a rapid increase in glutamate due to the direct inhibition of NMDARs localized to interneurons is involved in the antidepressant-like effects of (S)-norketamine (Fig. 2) ${ }^{125}$. Furthermore, we reported that, similar to $(S)$ ketamine, BDNF-TrkB and mTOR signaling might play a role in the antidepressant-like effects of $(S)$-norketamine in rodents ${ }^{125}$. Interestingly, the side effects of $(S)$-norketamine in rodents are significantly lower than those of $(S)$ ketamine; ketamine-induced side effects may be associated with NMDAR inhibition. Taken together, $(S)$-norketamine appears to be a safer alternative antidepressant without the side effects of (S)-ketamine in humans $^{12,125,126}$. Of note, unlike $(S)$-ketamine, $(S)$-norketamine is not a schedule compound.

\section{Conclusions}

The discovery of the antidepressant effects of ketamine in depressed patients was serendipitous ${ }^{24}$. The mechanisms underlying the antidepressant effects of ketamine have been investigated for almost 20 years, however, its precise molecular and cellular mechanisms remain to be fully elucidated. Although NMDAR inhibition is considered to serve a key role in the antidepressant effects of ketamine, clinical data of non-ketamine NMDAR antagonists (i.e., memantine, traxoprodil, lanicemine, rapastinel, and $\mathrm{AV}-101)^{12}$ and preclinical data using two ketamine enantiomers suggest that mechanisms other than NMDAR inhibition may be involved in the antidepressant effects of ketamine. For example, a randomized, placebo-controlled study using a large sample demonstrated that lanicemine did not exert antidepressant effects in patients with MDD with a history of inadequate treatment response ${ }^{127}$, supporting a lack of antidepressant-like effects of lanicemine in a CSDS model $^{128}$. On March 6, 2019, Allergan announced phase three results of rapastinel as an adjunctive treatment of MDD. In three acute trials, rapastinel treatment did not produce primary and key secondary endpoints compared with the placebo group. By contrast, rapastinel exerted rapid-acting antidepressant-like effects in a CSDS model although, unlike $(R)$-ketamine, rapastinel did not exhibit long-lasting antidepressant effects ${ }^{129}$. Collectively, nonketamine NMDAR antagonists did not produce robust ketamine-like antidepressant effects in patients with MDD, although certain NMDAR antagonists may exhibit rapid ketamine-like antidepressant-like effects in rodents. There is no guarantee that preclinical data will translate to humans ${ }^{130}$. At present, the general consensus is that
NMDAR inhibition and the subsequent AMPAR activation serve a role in the antidepressant-like effects of ketamine and two enantiomers. However, the precise molecular and cellular mechanisms underlying ketamine's antidepressant actions are complex ${ }^{5-10,94,131}$. Considering the clinical data and new preclinical data using ketamine enantiomers, it is the time to reconsider the current hypothesis for the antidepressant effects of ketamine. Recently, Heifets and Malenka ${ }^{130}$ suggested a need to conceptualize molecular mechanisms with more nuance than action at a single, broadly distributed glutamate receptor.

A number of researchers have used control stress-naive rodents to investigate the antidepressant-like effects of ketamine and its metabolites. Healthy control subjects showed significant increases in depressive symptoms for up to 1 day following a single ketamine infusion ${ }^{132}$, suggesting that ketamine does not produce antidepressant effects in healthy control subjects. It is also well known that ketamine can produce schizophrenia-like symptoms (i.e., positive symptoms, negative symptoms, cognitive impairment) in healthy control subjects ${ }^{32,38,133}$. Therefore, the use of control naive rodents may contribute to discrepancies in the antidepressant-like effects of ketamine and its metabolite $\mathrm{HNK}^{12,134}$. Collectively, rodents with depression-like phenotypes should be used to investigate the antidepressant effects of ketamine and its metabolites, although it is clear that animal models of depression cannot fully represent the complexity of human depression ${ }^{134,135}$.

On March 5, 2019, the US FDA approved (S)-ketamine nasal spray (Spravato ${ }^{\mathrm{TM}}$ ) for treatment-resistant depression. The clinical study of $(R)$-ketamine and $(2 R, 6 R)$-HNK in humans is currently underway ${ }^{12}$. Therefore, it is of interest to compare the antidepressant effects of $(R)$ ketamine and $(S)$-ketamine [or $(2 R, 6 R)-\mathrm{HNK}]$ in patients with MDD or BD. Finally, the identification of novel molecular and cellular targets responsible for the rapid and sustained antidepressant effects of enantiomers of ketamine and its metabolites is useful for the development of novel antidepressants without the detrimental side effects of ketamine.

\footnotetext{
Acknowledgements

This study was supported by grants from the National Natural Science Foundation of China (to C.Y., 81703482 and 81974171; to J.Y., 81771156; to A.L., 81771159 and 81571047), the AMED, Japan (to K.H., JP19dm0107119). C.Y. received the research support from B. Braun Medical Inc. K.H. is the inventor of filed patent applications on "The use of R-ketamine in the treatment of psychiatric diseases" and "(S)-norketamine and salt thereof as pharmaceutical" by the Chiba University. K.H. has received research support and consultant from Dainippon Sumitomo, Otsuka, and Taisho. J.Y. and A.L. report no biochemical financial interests or potential conflicts of interest.
}

\section{Author details}

${ }^{1}$ Department of Anesthesiology, Tongji Hospital, Tongji Medical College, Huazhong University of Science and Technology, Wuhan, China. ${ }^{2}$ Department 
of Anesthesiology, The First Affiliated Hospital of Zhengzhou University, Zhengzhou, China. ${ }^{3}$ Division of Clinical Neuroscience, Chiba University Center for Forensic Mental Health, Chiba, Japan. ${ }^{4}$ Present address: Department of Anesthesiology and Perioperative Medicine, The First Affiliated Hospital of Nanjing Medical University, Nanjing 210029, China

Received: 5 September 2019 Revised: 23 September 2019 Accepted: 20 October 2019

Published online: 07 November 2019

\section{References}

1. Trivedi, M. H. et al. Evaluation of outcomes with citalopram for depression using measurement-based care in STAR*D: implications for clinical practice. Am. J. Psychiatry 163, 28-40 (2006).

2. Bartoli, F. et al. Ketamine as a rapid-acting agent for suicidal ideation: a metaanalysis. Neurosci. Biobehav. Rev. 77, 232-236 (2017).

3. Wilkinson, S. T. et al. The effect of a single dose of intravenous ketamine on suicidal ideation: a systematic review and individual participant data metaanalysis. Am. J. Psychiatry 175, 150-158 (2018).

4. Hashimoto, K. Emerging role of glutamate in the pathophysiology of major depressive disorder. Brain Res. Rev. 61, 105-123 (2009).

5. Duman, R. S., Aghajanian, G. K., Sanacora, G. \& Krystal, J. H. Synaptic plasticity and depression: new insights from stress and rapid-acting antidepressants. Nat. Med. 22, 238-249 (2016).

6. Murrough, J. W. Abdallah, C. G. \& Mathew, S. J. Targeting glutamate signalling in depression: progress and prospects. Nat. Rev. Drug Discov. 16 472-486 (2017).

7. Abdallah, C. G., Sanacora, G., Duman, R. S. \& Krystal, J. H. The neurobiology of depression, ketamine and rapid-acting antidepressants: Is it glutamate inhibition or activation? Pharm. Ther. 190, 148-158 (2018).

8. Duman, R. S. Ketamine and rapid-acting antidepressants: a new era in the battle against depression and suicide. F1000Res. 7, 659 (2018).

9. Witkin, J. M., Knutson, D. E., Rodriguez, G. J. \& Shi, S. Rapid-acting antidepressants. Curr. Pharm. Des. 24, 2556-2563 (2018)

10. Gould, T. D., Zarate, C. A. Jr \& Thompson, S. M. Molecular pharmacology and neurobiology of rapid-acting antidepressants. Annu. Rev. Pharm. Toxicol. 59, 213-236 (2019).

11. Zhang, K. \& Hashimoto, K. An update on ketamine and its two enantiomers as rapid-acting antidepressants. Expert Rev. Neurother. 19, 83-92 (2019).

12. Hashimoto, K. Rapid-acting antidepressant ketamine, its metabolites and other candidates: a historical overview and future perspective. Psychiatry Clin. Neurosci. 73, 613-627 (2019).

13. Berman, R. M. et al. Antidepressant effects of ketamine in depressed patients. Biol. Psychiatry 47, 351-354 (2000).

14. Zarate, C. A. et al. A randomized trial of an N-methyl-D-aspartate antagonist in treatment-resistant major depression. Arch. Gen. Psychiatry 63, 856-864 (2006).

15. Diazgranados, N. et al. A randomized add-on trial of an N-methyl-D-aspartate antagonist in treatment-resistant bipolar depression. Arch. Gen. Psychiatry 67, 793-802 (2010).

16. Zarate, C. A. Jr. et al. Replication of ketamine's antidepressant efficacy in bipolar depression: a randomized controlled add-on trial. Biol. Psychiatry 71, 939-946 (2012).

17. Kraus, C. et al. Administration of ketamine for unipolar and bipolar depression. Int. J. Psychiatry Clin. Pract. 21, 2-12 (2017).

18. Zheng, W. et al. Rapid and longer-term antidepressant effects of repeateddose intravenous ketamine for patients with unipolar and bipolar depression. Psychiatry Res. 106, 61-68 (2018).

19. Price, R. B., Nock, M. K., Charney, D. S. \& Mathew, S. J. Effects of intravenous ketamine on explicit and implicit measures of suicidality in treatmentresistant depression. Biol. Psychiatry 66, 522-526 (2009).

20. Murrough, J. W. et al. Ketamine for rapid reduction of suicidal ideation: a randomized controlled trial. Psychol. Med. 45, 3571-3580 (2015).

21. Grunebaum, M. F. et al. Ketamine for rapid reduction of suicidal thoughts in major depression: a midazolam-controlled randomized clinical trial. Am. J. Psychiatry 175, 327-335 (2018).

22. Newport, D. J. et al. Ketamine and other NMDA antagonists: early clinical trials and possible mechanisms in depression. Am. J. Psychiatry 172, 950-966 (2015).
23. Kishimoto, T. et al. Single-dose infusion ketamine and non-ketamine $N$ methyl-D-aspartate receptor antagonists for unipolar and bipolar depression: a meta-analysis of efficacy, safety and time trajectories. Psychol. Med. 46, 1459-1472 (2016).

24. Krystal, J. H. et al. Ketamine: a paradigm shift for depression research and treatment. Neuron 101, 774-778 (2019).

25. Yang, C. \& Hashimoto, K. Rapid antidepressant effects and abuse liability of ketamine. Psychopharmacology 231, 2041-2042 (2014).

26. Liu, Y., Lin, D., Wu, B. \& Zhou, W. Ketamine abuse potential and use disorder. Neurosci. Bull. 126, 68-73 (2016).

27. Zhu, W. et al. Risks associated with misuse of ketamine as a rapid-acting antidepressant. Neurosci. Bull. 32, 557-564 (2016).

28. Singh, I. et al. Ketamine treatment for depression: opportunities for clinical innovation and ethical foresight. Lancet Psychiatry 4, 419-426 (2017).

29. Sanacora, G. et al. A consensus statement on the use of ketamine in the treatment of mood disorders. JAMA Psychiatry 74, 399-405 (2017).

30. Wilkinson, S. T. et al. A survey of the clinical, off-label use of ketamine as a treatment for psychiatric disorders. Am. J. Psychiatry 174, 695-696 (2017).

31. Short, B. et al. Side-effects associated with ketamine use in depression: a systematic review. Lancet Psychiatry 5, 65-78 (2018).

32. Javitt, D. C. \& Zukin, S. R. Recent advances in the phencyclidine model of schizophrenia. Am. J. Psychiatry 148, 1301-1308 (1991).

33. Fava, M. et al. Double-blind, placebo-controlled, dose-ranging trial of intravenous ketamine as adjunctive therapy in treatment-resistant depression (TRD). Mol. Psychiatry https://doi.org/10.1038/s41380-018-0256-5 (2018).

34. Luckenbaugh, D. A. et al. Do the dissociative side effects of ketamine mediate its antidepressant effects? J. Affect. Disord. 159, 56-61 (2014).

35. Deakin, J. F. et al. Glutamate and the neural basis of the subjective effects of ketamine: a pharmaco-magnetic resonance imaging study. Arch. Gen. Psychiatry 65, 154-164 (2008).

36. Wong, J. J. et al. Ketamine modulates subgenual cingulate connectivity with the memony-related neural circuit-a mechanism of relevance to resistant depression? PeerJ 4, e1710 (2016).

37. Ebert, B., Mikkelsen, S., Thorkildsen, C. \& Borgbjerg, F. M. Norketamine, the main metabolite of ketamine, is a non-competitive NMDA receptor antagonist in the rat cortex and spinal cord. Eur. J. Pharmacol. 333, 99-104 (1997).

38. Domino, E. F. Taming the ketamine tiger. 1965. Anesthesiology 113, 678-684 (2010).

39. Zhang, J. C., Li, S. X. \& Hashimoto, K. R(-)-ketamine shows greater potency and longer lasting antidepressant effects than $\mathrm{S}(+)$-ketamine. Pharm. Biochem. Behav. 116, 137-141 (2014).

40. Yang, C. et al. R-ketamine: a rapid-onset and sustained antidepressant without psychotomimetic side effects. Transl. Psychiatry 5, e632 (2015).

41. Zanos, P. et al. NMDAR inhibition-independent antidepressant actions of ketamine metabolites. Nature 533, 481-486 (2016).

42. Fukumoto, $\mathrm{K}$. et al. Antidepressant potential of (R)-Ketamine in rodent models: comparison with (S)-ketamine. J. Pharm. Exp. Ther. 361, 9-16 (2017).

43. Chang, L. et al. Comparison of antidepressant and side effects in mice after intranasal administration of (R,S)-ketamine, (R)-ketamine, and (S)-ketamine. Pharm. Biochem. Behav. 181, 53-59 (2019).

44. Yang, C. et al. Loss of parvalbumin-immunoreactivity in mouse brain regions after repeated intermittent administration of esketamine, but not $R$-ketamine. Psychiatry Res. 239, 281-283 (2016).

45. Tian, Z. et al. Expression of heat shock protein HSP-70 in the retrosplenial cortex of rat brain after administration of (R,S)-ketamine and (S)-ketamine, but not (R)-ketamine. Pharm. Biochem. Behav. 172, 17-21 (2018).

46. Hashimoto, $K$. et al. Reduction of dopamine $D_{2 / 3}$ receptor binding in the striatum after a single administration of esketamine, but not $R$-ketamine: a PET study in conscious monkeys. Eur. Arch. Psychiatry Clin. Neurosci. 267, 173-176 (2017).

47. Mathisen, L. C., Skjelbred, P., Skoglund, L. A. \& Oye, I. Effect of ketamine, an NMDA receptor inhibitor, in acute and chronic orofacial pain. Pain 61, 215-220 (1992).

48. Vollenweider, F. X. et al. Differential psychopathology and patterns of cerebral glucose utilisation produced by (S)- and (R)-ketamine in healthy volunteers using positron emission tomography (PET). Eur. Neuropsychopharmacol. 7, 25-38 (1997).

49. Zanos, P. et al. Ketamine and ketamine metabolite pharmacology: Insights into therapeutic mechanisms. Pharm. Rev. 70, 621-630. (2018).

50. Hashimoto, K. R-ketamine: a rapid-onset and sustained antidepressant without risk of brain toxicity. Psychol. Med. 46, 2449-2451 (2016). 
51. Hashimoto, K. Ketamine's antidepressant action: beyond NMDA receptor inhibition. Expert Opin. Ther. Targets 20, 1389-1392 (2016).

52. Hashimoto, K. Detrimental side effects of repeated ketamine infusions in the brain. Am. J. Psychiatry 173, 1044-1045 (2016).

53. Trullas, R. \& Skolnick, P. Functional antagonists at the NMDA receptor complex exhibit antidepressant actions. Eur. J. Pharmacol. 185, 1-10 (1990).

54. Skolnick, P., Popik, P. \& Trullas, R. Glutamate-based antidepressants: 20 years on. Trends Pharm. Sci. 30, 563-569 (2009).

55. Maeng, S. et al. Cellular mechanisms underlying the antidepressant effects of ketamine: role of alpha-amino-3-hydroxy-5-methylisoxazole-4-propionic acid receptors. Biol. Psychiatry 63, 349-352 (2008).

56. Li, N. et al. mTOR-dependent synapse formation underlies the rapid antidepressant effects of NMDA antagonists. Science 329, 959-964 (2010).

57. Autry, A. E. et al. NMDA receptor blockade at rest triggers rapid behavioural antidepressant responses. Nature 475, 91-95 (2011)

58. Monteggia, L. M. \& Zarate, C. A. Jr. Antidepressant actions of ketamine: from molecular mechanisms to clinical practice. Curr. Opin. Neurobiol. 30, 139-143 (2015).

59. Masaki, Y., Kashiwagi, Y., Watabe, H. \& Abe, K. (R)- and (S)-ketamine induce differential fMRI responses in conscious rats. Synapse 73, e22126 (2019).

60. Ago, Y. et al. (R)-ketamine induces a greater increase in prefrontal 5-HT release than (S)-ketamine and ketamine metabolites via an AMPA receptorindependent mechanism. Int. J. Neuropsychopharmacol. 22, 665-674 (2019).

61. Zhang, K. et al. 5-Hydroxytryptamine-independent antidepressant actions of (R)-ketamine in a chronic social defeat stress model. Int. J. Neuropsychopharmacol. 21, 157-163 (2018).

62. Hare, B. D. et al. Optogenetic stimulation of medial prefrontal cortex Drd1 neurons produces rapid and long-lasting antidepressant effects. Nat. Commun. 10, 223 (2019).

63. Chang, L. et al. Lack of dopamine $D_{1}$ receptors in the antidepressant actions of (R)-ketamine in a chronic social defeat stress model. Eur. Arch. Psychiatry Clin. Neurosci. https://doi.org/10.1007/s00406-019-01012-1 (2019).

64. Li, Y. et al. Dopamine $D_{2} / D_{3}$ but not dopamine $D_{1}$ receptors are involved in the rapid antidepressant-like effects of ketamine in the forced swim test. Behav. Brain Res. 279, 100-105 (2015).

65. Saxton, R. A. \& Sabatini, D. M. mTOR signaling in growth, metabolism, and disease. Cell 168, 960-976 (2017).

66. Switon, K. et al. Molecular neurobiology of mTOR. Neuroscience 341, 112-153 (2017).

67. Yang, C. et al. Acute administration of ketamine in rats increases hippocampal BDNF and mTOR levels during forced swimming test. Ups. J. Med. Sci. 118, 3-8 (2013).

68. Yang, $C$. et al. Tramadol pretreatment enhances ketamine-induced antidepressant effects and increases mammalian target of rapamycin in rat hippocampus and prefrontal cortex. J. Biomed. Biotechnol. 2012, 175619 (2012).

69. Paul, R. K. et al. (R,S)-Ketamine metabolites (R,S)-norketamine and (2S,6S)hydroxynorketamine increase the mammalian target of rapamycin function. Anesthesiology 121, 149-159 (2014).

70. Hadamitzky, M. et al. Acute systemic rapamycin induces neurobehavioral alterations in rats. Behav. Brain Res. 273, 16-22 (2014).

71. Shen, M. et al. Essential roles of neuropeptide VGF regulated TrkB/mTOR/ BICC1 signaling and phosphorylation of AMPA receptor subunit GluA1 in the rapid antidepressant-like actions of ketamine in mice. Brain Res. Bull. 143, 58-65 (2018).

72. Llamosas, N. et al. Ketamine promotes rapid and transient activation of AMPA receptor-mediated synaptic transmission in the dorsal raphe nucleus. Prog. Neuropsychopharmacol. Biol. Psychiatry 88, 243-252 (2019).

73. Abelaira, H. M. et al. Ketamine exhibits different neuroanatomical profile after mammalian target of rapamycin inhibition in the prefrontal cortex: the role of inflammation and oxidative stress. Mol. Neurobiol. 54, 5335-5346 (2017).

74. Abelaira, H. M. et al. Effects of ketamine administration on mTOR and reticulum stress signaling pathways in the brain after the infusion of rapamycin into prefrontal cortex. J. Psychiatr. Res. 87, 81-87 (2017).

75. Chiu, C. T. et al. The mood stabilizer lithium potentiates the antidepressant-like effects and ameliorates oxidative stress induced by acute ketamine in a mouse model of stress. Int. J. Neuropsychopharmacol. 18, pyu102 (2014).

76. Zhou, W. et al. Ketamine-induced antidepressant effects are associated with AMPA receptors-mediated upregulation of $\mathrm{mTOR}$ and BDNF in rat hippocampus and prefrontal cortex. Eur. Psychiatry 29, 419-423 (2014).
77. Yang, C. et al. Mechanistic target of rapamycin-independent antidepressant effects of (R)-ketamine in a social defeat stress model. Biol. Psychiatry $\mathbf{8 3}$, 18-28 (2018).

78. Denk, M. C. et al. Monitoring ketamine treatment response in a depressed patient via peripheral mammalian target of rapamycin activation. Am. J. Psychiatry 168, 751-752 (2011).

79. Yang, C. et al. Acute increases in plasma mammalian target of rapamycin, glycogen synthase kinase-3beta, and eukaryotic elongation factor 2 phosphorylation after ketamine treatment in three depressed patients. Biol. Psychiatry 73, e35-e36 (2013).

80. Abdallah, C. G., et al. Rapamycin, an immunosuppressant and mTORC1 inhibitor, triples the antidepressant response rate of ketamine at 2 weeks following treatment. Preprint at https://doi.org/10.1101/500959 (2018).

81. Nestler, E. J. et al. Neurobiology of depression. Neuron 34, 13-25 (2002).

82. Hashimoto, K., Shimizu, E. \& lyo, M. Critical role of brain-derived neurotrophic factor in mood disorders. Brain Res. Brain Res. Rev. 45, 104-114 (2004).

83. Duman, R. S. \& Monteggia, L. M. A neurotrophic model for stress-related mood disorders. Biol. Psychiatry 59, 1116-1127 (2006).

84. Hashimoto, K. Brain-derived neurotrophic factor as a biomarker for mood disorders: an historical overview and future directions. Psychiatry Clin. Neurosci. 64, 341-357 (2010).

85. Björkholm, C. \& Monteggia, L. M. BDNF-a key transducer of antidepressant effects. Neuropharmacology 102, 72-79 (2016).

86. Zhang, J. C., Yao, W. \& Hashimoto, K. Brain-derived neurotrophic factor (BDNF)-TrkB signaling in inflammation-related depression and potential therapeutic targets. Curr. Neuropharmacol. 14, 721-731 (2016).

87. Zhan, G. et al. PGC-1a-FNDC5-BDNF signaling pathway in skeletal muscle confers resilience to stress in mice subjected to chronic social defeat. Psychopharmacology 235, 3351-3358 (2018).

88. Liu, W. X. et al. Regulation of glutamate transporter 1 via BDNF-TrkB signaling plays a role in the anti-apoptotic and antidepressant effects of ketamine in chronic unpredictable stress model of depression. Psychopharmacology 233, 405-415 (2016).

89. Tornese, P. et al. Chronic mild stress induces anhedonic behavior and changes in glutamate release, BDNF trafficking and dendrite morphology only in stress vulnerable rats. The rapid restorative action of ketamine. Neurobiol. Stress 10, 100160 (2019).

90. Kohtala, S. et al. Ketamine-induced regulation of TrkB-GSK3 $\beta$ signaling is accompanied by slow EEG oscillations and sedation but is independent of hydroxynorketamine metabolites. Neuropharmacology 157, 107684 (2019).

91. Duman, R. S. \& Aghajanian, G. K. Synaptic dysfunction in depression: potential therapeutic targets. Science 338, 68-72 (2012).

92. Duman, C. H. \& Duman, R. S. Spine synapse remodeling in the pathophysiology and treatment of depression. Neurosci. Lett. 601, 20-29 (2015).

93. Ohgi, Y., Futamura, T. \& Hashimoto, K. Glutamate signaling in synaptogenesis and NMDA receptors as potential therapeutic targets for psychiatric disorders. Curr. Mol. Med. 15, 206-221 (2015).

94. Duman, R. S., Shinohara, R., Fogaça, M. V. \& Hare, B. Neurobiology of rapidacting antidepressants: convergent effects on GluA1-synaptic function. Mol. Psychiatry https://doi.org/10.1038/s41380-019-0400-x (2019).

95. Dong, C. et al. Rapid and sustained antidepressant action of the mGlu2/3 receptor antagonist MGS0039 in the social defeat stress model: comparison with ketamine. Int. J. Neuropsychopharmacol. 20, 228-236 (2017)

96. Moda-Sava, R. N. et al. Sustained rescue of prefrontal circuit dysfunction by antidepressant-induced spine formation. Science 364, pii: eaat8078 (2019).

97. Zhang, J. et al. (R)-ketamine rapidly ameliorates the decreased spine density in the medial prefrontal cortex and hippocampus of susceptible mice after chronic social defeat stress. Int. J. Neuropsychopharmacol. 22, 675-679 (2019).

98. Treccani, G. et al. S-Ketamine reverses hippocampal dendritic spine deficits in Flinders sensitive line rats within $1 \mathrm{~h}$ of administration. Mol. Neurobiol. 56, 7368-7379 (2019).

99. Hirota, K. \& Lambert, D. G. Ketamine: its mechanism(s) of action and unusual clinical uses. Br. J. Anaesth. 77, 441-444 (1996).

100. Williams, N. R. et al. Attenuation of antidepressant effects of ketamine by opioid receptor antagonisms. Am. J. Psychiatry 175, 1205-1215 (2018).

101. Williams, N. R. et al. Attenuation of antidepressant and antisuicidal effects of ketamine by opioid receptor antagonisms. Mol. Psychiatry https://doi.org/ 10.1038/s41380-019-0503-4 (2019).

102. Yoon, G., Petrakis, I. L. \& Krystal, J. H. Association of combined naltrexone and ketamine with depressive symptoms in a case series of patients with depression and alcohol use disorder. JAMA Psychiatry 176, 337-338 (2019). 
103. Marton, T., Barnes, D. E., Wallace, A. \& Woolley, J. D. Concurrent use of buprenorphine, methadone, or naltrexone does not inhibit ketamine's antidepressant activity. Biol. Psychiatry 85, e76-e76 (2019).

104. Zhang, K. \& Hashimoto, K. Lack of opioid system in the antidepressant actions of ketamine. Biol. Psychiatry 85, e25-e27 (2019).

105. Zarate, C. A. Jr et al. Relationship of ketamine's plasma metabolites with response, diagnosis, and side effects in major depression. Biol. Psychiatry $\mathbf{7 2}$, 331-338 (2012)

106. Pham, T. H. et al. Common neurotransmission recruited in (R,S)-ketamine and $(2 R, 6 R)$-hydroxynorketamine-induced sustained antidepressant-like effects. Biol. Psychiatry 84, e3-e6 (2018).

107. Fukumoto, K. et al. Activity-dependent brain-derived neurotrophic factor signaling is required for the antidepressant actions of $(2 R, 6 R)$-hydroxynorketamine. Proc. Natl Acad. Sci. USA 116, 97-302 (2019).

108. Lumsden, E. W. et al. Antidepressant-relevant concentrations of the ketamine metabolite $(2 R, 6 R)$-hydroxynorketamine do not block NMDA receptor function. Proc. Natl Acad. Sci. USA 116, 5160-5169 (2019).

109. Suzuki, K. et al. Effects of a ketamine metabolite on synaptic NMDAR function. Nature 546, E1-E3 (2017).

110. Zanos, P. et al. (2R,6R)-hydroxynorketamine exerts mGlu2 receptordependent antidepressant actions. Proc. Natl Acad. Sci. USA 116 6441-6450 (2019).

111. Yang, $C$. et al. (R)-ketamine shows greater potency and longer lasting antidepressant effects than its metabolite $(2 R, 6 R)$-hydroxynorketamine. Biol. Psychiatry 82, e43-e44 (2017).

112. Shirayama, Y. \& Hashimoto, K. Lack of antidepressant effects of $(2 R, 6 R)$ hydroxynorketamine in a rat learned helplessness model: comparison with (R)-ketamine. Int. J. Neuropsychopharmacol. 21, 84-88 (2018).

113. Zhang, K., Fujita, Y. \& Hashimoto, K. Lack of metabolism in (R)-ketamine's antidepressant actions in a chronic social defeat stress model. Sci. Rep. 8, 4007 (2018).

114. Zhang, K. et al. Lack of deuterium isotope effects in the antidepressant effects of (R)-ketamine in a chronic social defeat stress model. Psychopharmacology 235, 3177-3185 (2018).

115. Chang, L. et al. No sex-specific differences in the acute antidepressant actions of $(R)$-ketamine in an inflammation model. Int. J. Neuropsychopharmacol. 21, 932-937 (2018).

116. Xiong, Z. et al. Beneficial effects of $(R)$-ketamine, but not its metabolite $(2 R, 6 R)$-hydroxynorketamine, in the depression-like phenotype, inflammatory bone markers, and bone mineral density in a chronic social defeat stress model. Behav. Brain Res. 368, 111904 (2019).

117. Yamaguchi, J. I. et al. $(2 R, 6 R)$-Hydroxynorketamine is not essential for the antidepressant actions of (R)-ketamine in mice. Neuropsychopharmacology 235, 1900-1907 (2016)

118. Shirayama, Y. \& Hashimoto, K. Effects of a single bilateral infusion of $R$ ketamine in the rat brain regions of a learned helplessness model of depression. Eur. Arch. Psychiatry Clin. Neurosci. 267, 177-182 (2017).
119. Chaki, S. Is metabolism of (R)-ketamine essential for the antidepressant effects? Int. J. Neuropharmacol. 21, 154-156 (2018).

120. Chaki, S. \& Yamaguchi, J. I. Now is the time for (2R,6R)-hydroxynorketamine to be viewed independently from its parent drug. Pharm. Biochem. Behav. 175 24-26 (2018).

121. Zanos, P. et al. (R)-ketamine exerts antidepressant actions partly via conversion to $(2 R, 6 R)$-hydroxynorketamine, while causing adverse effects at subanaesthetic doses. Bri. J. Pharmacol. 176, 2573-2592 (2019).

122. Shaffer, C. L. et al. Pharmacological evaluation of clinically relevant concentrations of $(2 R, 6 R)$-hydroxynorketamine. Neuropharmacology 153, 73-81 (2019).

123. Nations, K. R. et al. Examination of Org 26576, an AMPA receptor positive allosteric modulator, in patients diagnosed with major depressive disorder: an exploratory, randomized, double-blind, placebo-controlled trial. J. Psychopharmacol. 26, 1525-1539 (2012).

124. Ye, L. et al. Ketamine metabolite $(2 R, 6 R)$-hydroxynorketamine enhances aggression via periaqueductal gray glutamatergic transmission. Neuropharmacology 157, 107667 (2019).

125. Yang, C. et al. AMPA receptor activation-independent antidepressant actions of ketamine metabolite (S)-norketamine. Biol. Psychiatry 84, 591-600 (2018).

126. Hashimoto, K. \& Yang, C. Is (S)-norketamine an alternative antidepressant for esketamine? Eur. Arch. Psychiatry Clin. Neurosci. 269, 867-868 (2019).

127. Sanacora, G. et al. Adjunctive lanicemine (AZD6765) in patients with major depressive disorder and history of inadequate response to antidepressants: a randomized, placebo-controlled study. Neuropsychopharmacology $\mathbf{4 2}$ 844-853 (2017).

128. Qu, Y. et al. Comparison of (R)-ketamine and lanicemine on depression-like phenotype and abnormal composition of gut microbiota in a social defeat stress model. Sci. Rep. 7, 15725 (2017)

129. Yang, B. et al. Comparison of R-ketamine and rapastinel antidepressant effects in the social defeat stress model of depression. Psychopharmacology 233, 3647-3657 (2016)

130. Heifets, B. D. \& Malenka, R. C. Disruptive psychopharmacology. JAMA Psychiatry https://doi.org/10.1001/jamapsychiatry.2019.1145 (2019).

131. Kadriu, B. et al. Glutamatergic neurotransmission: pathway to developing novel rapid-acting antidepressant treatments. Int. J. Neuropsychopharmacol. 22, 119-135 (2019).

132. Nugent, A. C. et al. Ketamine has distinct electrophysiological and behaviora effects in depressed and healthy subjects. Mol. Psychiatry 24, 1040-1052 (2019).

133. Krystal, J. H. et al. Subanesthetic effects of the noncompetitive NMDA antagonist, ketamine, in humans. Psychotomimetic, perceptual, cognitive, and neuroendocrine responses. Arch. Gen. Psychiatry 51, 199-214 (1994).

134. Hashimoto, K. \& Shirayama, Y. What are the causes for discrepancies of antidepressant actions of (2R,6R)-hydroxynorketamine? Biol. Psychiatry $\mathbf{8 4}$ e7-e8 (2018).

135. Bale, T. L. et al. The critical importance of basic animal research for neuropsychiatric disorders. Neuropsychopharmacology 44, 1349-1353 (2019). 